\title{
VALENTE Y LA PALABRA SUMERGIDA
}

\section{VALENTE OR THE WORD SUBMERGED}

\author{
José Andújar Almansa \\ Crítico literario
}

Resumen:A lo largo de este artículo, dividido en dos partes, se hace una valoración global de la poesía deValente, atendiendo al especial vínculo que dentro de su obra mantuvieron la palabra-creativa y la palabra-pensamiento. En el primer apartado, "Hasta dónde llega una palabra», se muestran las reflexiones del autor acerca de "el lugar del canto", ese espacio que ya desde sus libros iniciales sintió la necesidad de levantar sobre la morada arruinada del lenguaje, en un "tiempo de miseria» y retóricas usurpadoras del verdadero decir poético. De manera paralela, se produce en Valente la conquista de una tradición literaria propia, fruto del acercamiento a las principales corrientes de la literatura, las artes plásticas, la música, la filosofia y la reflexión estética contemporánea. Los nombres de Juan Ramón, Cernuda, Celan, Jabès, María Zambrano, Webern o Tàpies representan algunos de los principales hitos dentro de ese itinerario, que tiene su reflejo más temprano en las páginas de Las palabras de la tribu y su Diario anónimo. La segunda parte, «La palabra sumergida», transita a lo largo de todos sus libros, prescindiendo de la cronología o las llamadas «etapas» de Valente, tan proclives a crear una ortodoxia en torno al autor. Con la expresión "palabra sumergida» se hace mención a distintos registros de su poética: la necesidad de mantenerse al margen de la superficie que llamamos actualidad, su acercamiento a los procedimientos creativos de la mística, su visión de lo inefable como un sustrato que forma parte de los depósitos del lenguaje o sus relaciones entre la atonalidad, el fragmentarismo y una estética del silencio. El propósito es demostrar que la palabra sumergida de Valente es una palabra afirmadora, que nunca enmudece ni cae en un nihilismo estéril. Poeta de la radical inmanencia y de la memoria material del mundo, es posible discernir a lo largo de su obra una «metafísica del arte», en los términos en que la concibieron Nietzsche o Heidegger.

Palabras Clave: José ÁngelValente; poesía española contemporánea; Juan Ramón Jiménez; Luis Cernuda;Valente traductor; Paul Celan; poéticas del fragmento; estética del silencio.

Aвstract: Through out this essay, divided into two parts, a global assessment of Valente's poetry is made, taking into account the special link that the creative-word and the thought-word maintained in his work. In the first section, «How far does a word go", the authors reflections on "El lugar del canto» are shown, that space 
which he felt the need to build, on the ruined home of language from his very first books, in a «Time of Misery» and usurping rhetoric of true poetic saying. In parallel, there is the conquest of a literary tradition in Valente, the result of the approach to the main trends of literature, plastic arts, music, philosophy and contemporary aesthetic reflection. The names of Juan Ramón, Cernuda, Celan, Jabès, María Zambrano,Webern or Tàpies represent some of the main milestones within that itinerary, which has its earliest reflection in the pages of Las palabras de la tribu and Diario anónimo. The second part, "The word submerged», travels through out all his books, regardless of the chronology or the so-called «stages» of Valente, so likely to create an orthodoxy around the author.With the expression «Submerged Word» different records of his poetics are referred to: the need to stay away from the surface that we call current existence, his approach to the creative processes of mysticism, his vision of the ineffable as a substratum that is part of the deposits of language, or the relationships between atonality and fragmentation with an aesthetic of silence. The purpose is to demonstrate thatValente's submerged word is an asserting word, which never keeps silent or leads to vain nihilism. Poet of the radical immanence and the material memory of the world, it is posible to discern through out his work a kind of "metaphysics of art», in the terms conceived by Nietzsche or Heidegger.

KeY wORDS: José Ángel Valente; Spanish Contemporary poetry; Juan Ramón Jiménez; Luis Cernuda; traduction by Valente; Paul Celan; the fragmentary poetics; aesthetic of silence.

\section{HASTA DÓNDE LLEGA UNA PALABRA}

Hay un ensayo en Las palabras de la tribu (1971), «El lugar del canto» (II: 50-53) ${ }^{1}$, que comparte título con un texto de Poemas a Lázaro (1960): «Sobre el lugar del canto» (I: 149-150). En realidad, se trata de ambas caras de una misma moneda. Esa y otras monedas las lanza Valente al aire para que veamos oscilar, alternativamente, secuencias de poesía y pensamiento que integran un único proceso creativo. Se escribe siempre desde un lugar, y preguntarse acerca de la naturaleza de este supone eludir una primera barrera de ingenuidades. La escritura es en gran medida un acto de des-escribir o re-escribir: desvanecer el rastro de todo lo que es estable, o regresar a lo que ha sido borrado, derruido. Para referirse a ese acto Valente hizo suyos

1 Todas las citas de poemas, versos aislados, ensayos críticos o traducciones realizadas por Valente se indican en el texto atendiendo a la edición de los dos volúmenes de sus Obras completas, editados en 2006 y 2008 por Andrés Sánchez Robayna. Para abreviar, mencionaré solo número de volumen y página. 
unos versos de René Char: «Les mots qui vont surgir savent de nous ce que nous / ignorons d'eux» («Las palabras que van a surgir saben de nosotros lo que nosotros / ignoramos de ellas»).

Por eso, cuando acude a un desarrollo teórico en el que el término lugar aparece diferenciado respecto al de patria, entendemos que tal distinción, dentro de ese ecosistema llamado Valente, trasluce el germen de una equivalencia mucho más clarificadora. La distancia que media entre la palabra como espacio abierto a lo poético y todas las excrecencias adheridas cuando esta resulta pasto de la historia. Excrecencias dictadas desde la sala de prensa, la tribuna o el púlpito. Valente redactó los ensayos que componen Las palabras de la tribu entre 1955 y 1970, el mismo periodo que abarca composiciones de la relevancia de «Patria, cuyo nombre no sé», «Sobre el tiempo presente» o el ya citado «Sobre el lugar del canto». Es comprensible que poesía y reflexión poética arrastren a lo largo de aquellos años la carga de un pesado equipaje histórico. Por tal motivo, los versos «este es el lugar que un día / fue solar prodigioso de una casa más grande» (I: 150) no pueden leerse únicamente en clave heideggeriana del lenguaje como casa arruinada. O sí. Pero dejando claro que desde ese solar de palabras desmoronadas debe tenderse una escala para alcanzar de nuevo el discurso del hombre, aunque sea sobre una montaña de escombros. En «Sobre el lugar del canto» Valente denuncia por igual la barbarie sufrida por todo un país y las retóricas usurpadoras de la lengua contra las que ha de fundar un poeta español de la posguerra su canto verdadero:

La mentira y sus vástagos.

El odio

espeso y su constelación de sombra.

La cólera terrible de la tierra

que no alimenta la raíz del aire

y se acuesta en la tierra boca abajo.

La palabra que nace sin destino.

La sangre que no siembra más que sangre.

El pan desposeído de la casa del hombre [...]

Esta es la hora, este es el tiempo

- hijo soy de esta historia-

este el lugar que un día

fue solar prodigioso de una casa más grande (I: 149-150). 
La palabra "nace sin destino", arrojada a una oscura travesía hasta lograr desprenderse de su tenebrosa carga de mentira, de violencia, de infamia. Por eso su primer libro de ensayos, un libro alejado por igual del costumbrismo crítico que de las pedanterías academicistas, toma el título que Mallarmé esculpió en un verso para «La tumba de Edgar Poe»: aquel que impele a todo escritor a «donner un sens plus pur aux mots de la tribu». Dar un sentido más puro es devolver el lenguaje a su verdad, distanciarlo del falseamiento que representa toda instrumentalización pública. Para ser objetivos, Valente muestra todavía en estas páginas una postura equidistante entre la lira pura de Mallarmé y la posibilidad histórica de la «restauración de un lenguaje comunitario deteriorado y corrupto» (II: 78); a lo que añade al respecto en una entrada de 1965 de su Diario anónimo: «He aquí una función radicalmente social del arte» (2011: 88). Solo así se explica que el posterior autor de Elogio del calígrafo (2002) se postule, en una fecha aún más temprana dentro del mismo diario, abiertamente en contra de la pintura abstracta (de la que se nutrirá después con jugoso provecho para su andadura creativa). Pero elValente de esos primeros años busca una certeza de conexión estética entre el hombre y la realidad, mientras que «el artista abstracto al escamotear esta relación lleva el arte al plano hermoso de la cristalografia, donde la belleza del cuadro abstracto resultará siempre pobre y limitada» (2011:55). ¿Atenta esto contra la ensalzada heterodoxia del poeta? Todo es matizable. El verdadero creador mantiene una relación paradójica con su tiempo: es hijo indudable de este, aunque no le conviene coincidir demasiado. Vive una intermitente contemporaneidad en la que ni los hechos históricos ni el salvoconducto de la norma literaria le garantizan acceder a su obra. Valente coincidió lo preciso, para acabar siendo cada vez más extemporáneo e intempestivo, quiero decir menos previsible a la hora de expresar algo que en verdad no sepamos. Si nos remitimos a los primeros libros, interpretó su labor sin caer en las miopías de un realismo convertido en tendencia. No le interesó un ejercicio de mímesis, sino la manera en que el arte logra una mediación entre el hombre y la realidad. ¿Cómo, si no, concebir la esperanza de levantar una poética y una historia a partir tan solo de palabras caídas? "Patria, cuyo nombre no sé» discurre por esa tesitura:

La tierra había sido removida y arada con la sangre de todos. 


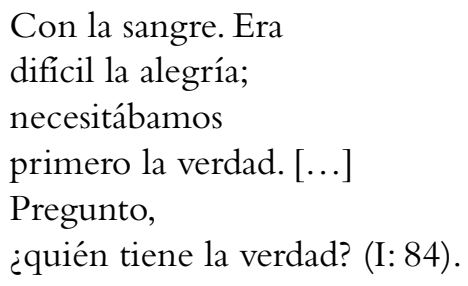

En vez de la verdad, encontró banderas agitadas por sonidos huecos emitidos por hombres huecos. Valente, que mostró su repulsa en los versos de «Poeta en tiempo de miseria» (I: 199-200), bien podría haber escrito parecidas estrofas sobre poetas en tiempo de mentira. En «Epitafio» (I: 205-206), dedicado a la memoria de Alberto Jiménez Fraud, cuyo destierro se tradujo en una forma de habitar la patria única del pensamiento, igual que el protagonista de otro de sus mejores poemas, "Maquiavelo en San Casciano» (I: 206-208), encontramos el testimonio que declara la conciencia de una misión heredada y transmitida: «Testigo de más fe, para hacernos más libres, / guardó de las palabras / en tiempo de mentira / la fuente verdadera» (I: 206). En Valente, la búsqueda de un sentido, o de los múltiples estratos de sentido, para restituir la experiencia histórica y volver a fundar "el lugar del canto", esto es, "para hacernos más libres» y conservar la «fuente verdadera», se convirtió en una hermenéutica que describe a lo largo de Las palabras de la tribu un doble itinerario, a la vez especulativo y estético. Ahí están para atestiguarlo los nombres de Auden, Antonio Machado,Valéry, Eliot, Foucault, Montale, Hölderlin, Juan Ramón Jiménez, Enzensberger, Cavafis, Benjamin, Cernuda, Blanchot, Lorca, Vallejo, Unamuno, Rilke, Giner de los Ríos, Lezama Lima, María Zambrano o Borges entre otros, que nos transmiten la imagen de unValente con la férrea determinación de ser poeta pese a aquel «tiempo de miseria».

Después, como resultado de un desarrollo intelectual y artístico en continua expansión, acaecerán otros advenimientos ineludibles: Celan, Edmond Jabès, Westphalen, Spinoza, Wittgenstein; la mística desde todos los ámbitos: del maestro Eckhart a Scholem, pasando por las presencias imantadas de Juan de la Cruz, Teresa de Ávila y Miguel de Molinos; la música de Schönberg y Webern; la pintura de Tàpies y Bacon; la escultura de Chillida... La lista llega a ser admirable y por momentos nos abruma. La muy oportuna recopilación hecha por Rodríguez Fer de la labor traductora del poeta en Cuaderno de versiones (2002), así como el heteróclito dietario que el autor denominó Diario anónimo, y la reciente publicación de sus 
diálogos y entrevistas en El ángel de la creación (2018), arrojan luz y matizan el periplo de una exigencia de curiosidad estética que se antoja inagotable.

¿Cuál de estas figuras resultó más esencial para Valente? Sin duda, todas proyectaron sobre él su sombra, con la que estableció un profundo y duradero diálogo.Valente fue un poeta de lo que llamó Eliot Weinberger «rastros kármicos» (2012: 101), un concepto de tradición artística como transmisión, en la que los vivos modifican a los muertos, y los muertos revisan sus propias creaciones por medio de los vivos.Voces de vivos y muertos le otorgaron su compañía para mostrarle, a su vez, el inevitable desarraigo literario, lingüístico, canónico, e incluso generacional, que hace del auténtico poeta un ser de intemperie.Valente aceptó el pacto, y lo firma en los versos: «Porque es nuestro el exilio. / No el reino» (I: 276). Situarse en el centro de la modernidad lírica supone asumir que esa centralidad, como adujo Octavio Paz en La otra voz, resulta por definición «excéntrica» frente a las geometrías del progreso o la historia (1999: 697).

Excéntrico se nos muestra Valente, intentando convertir en plática el fascinante soliloquio de «A don Francisco de Quevedo, en piedra» (I: 143-145), en realidad una conversación entre la intemperie de piedra del maestro y la del joven escritor lleno de dudas: «Bajo cada mañana / al café de la esquina, / resonante de vida, / y sorbo cuanto puedo / el día que comienza» (I: 143). Si resulta «dificil entenderse, / fácil sentir lo mismo» (I: 144) es porque ambos cruzan en el aire un debate desolado: «Dime qué ves desde tu altura. / Pero tal vez lo mismo. Muros, campos, / solar de insolaciones» (I: 145). La poesía: las voces que oyen los poetas y la «otra voz» que dice a menudo lo que la sociedad o el poder no quieren oír. «Solar de insolaciones».

¿El exilio o el reino? Más bien exilio o deserción. Pues no hay conciencia creadora sin resistencia, sin desarreglo, sin rechazo del alma.Valente, cuya ética de escritura fue de naturaleza exílica, se vio obligado a consolidar biográficamente tal actitud con sus largas estancias en Oxford, Ginebra y París. En el poema que abre su primera antología, titulada no por casualidad Sobre el lugar del canto (1963), vuelve a expresar sus dudas: «Bajo otro cielo y otra luz lejanos / no puedo hablar» (1963:9). Lo que me recuerda que Ajmátova escribió justamente lo contrario (¿o en el fondo lo mismo?) al comienzo de su Réquiem: «No me amparaba ningún cielo extranjero, / no, alas 
extranjeras no me protegían. / Estaba entonces entre mi pueblo / y con él compartía su desgracia» (2005: 39). Valente comprendió muy pronto que no hay amparo posible para la palabra poética, una palabra de condición extranjera bajo cualquier cielo, lo que tal vez explica que no volviera a recoger este poema en libro. Pero liberarse del angosto callejón histórico y literario de la patria le permitió, a cambio, abrir numerosas puertas y ventanas, ahondando en las diversas tradiciones de la vanguardia y el postsimbolismo europeo. Y de ahí propiciar el reencuentro con el propio idioma en lo que Juan Ramón Jiménez llamara el «otro costado» de la lengua, ese que Valente reintegraría a su único organismo impulsando la antología Las ínsulas extrañas (2002).

En su calidad de Strong poet, Valente no sufrió la «ansiedad de las influencias». Muy al contrario, supo apropiarse con naturalidad de la herencia que comprende todo aquello que quedó en pie après le déluge de Rimbaud para ser absolument moderne. Esto quiere decir que absorbió la tradición desde postulados que pertenecen a la vanguardia. $\mathrm{O}$ sea, manteniendo la sospecha hacia el presente y la máxima ironía frente al pasado. El procedimiento conduce a una sintaxis artística que imposibilita su asimilación por una lógica cultural transformada en lógica del consumo, cuya escasa relevancia simbólica rebaja nuestra percepción de la realidad y nos condena al relato de un tiempo que carece de tiempo, pues vive en las ficciones de la inmediatez (Speranza, 2017). Algunos de los libros de Valente, como Presentación y memorial para un monumento (1970), Treinta y siete fragmentos (1971), Material memoria (1979), Tres lecciones de tinieblas (1980), Mandorla (1982) o No amanece el cantor (1992), se incluyen dentro de lo que podríamos considerar el tránsito ininterrumpido de las rupturas singulares que impulsan el arte, esa única forma posible de diálogo que nos resta hoy con lo que ha llamado Damián Tabarovsky Fantasma de la vanguardia. ¿Y cómo se entabla conversación con un fantasma? Un fantasma «no es como los zombis, que son la muerte después de la muerte [...] Un fantasma, en cambio, está ahí, flotando, entrando y saliendo, apareciendo y desapareciendo [...] A veces el fantasma nos habla y no lo escuchamos. A veces le hablamos y no nos responde. No obstante, ese diálogo imposible sigue siendo un horizonte imprescindible para la literatura contemporánea» (Tabarovsky, 2018: 11). Donde subraya Tabarovsky «horizonte imprescindible», sitúa Valente "el lugar del canto». 
El acto de escribir en Valente tuvo algo de espiritismo; escribió percibiendo bajo la página múltiples corrientes sumergidas. En una entrada de 1974, anota en Diario anónimo: «Disolver en el contenido de la tradición la experiencia personal, con lo que la tradición no se repite sino que se continúa o se recomienza» (2011:160).Algo o mucho de eso hay en Espacio de Juan Ramón Jiménez, donde su empeño de totalidad no debe confundirnos, ni confundió a Valente. Espacio conforma un deslumbrante collage, una sucesión de fragmentos donde el súper-yo de Juan Ramón se diluye en el fluir de una secuencia de imágenes interpretadas por él como conciencia cósmica, pero que en realidad se remite a la conciencia de la poesía occidental. Tiene razón Jiménez Heffernan cuando afirma que Juan Ramón constituye uno de los precursores fuertes deValente, y que Animal de fondo y Espacio son libros de los que «no logra escapar» $(2004: 193,195)$. Discernir por separado el modo en que la tradición (esa corriente que todo gran poeta no repite, sino que continúa o recomienza) deja su rastro en una obra de extraordinarios logros como la deValente se adivina complejo. Por eso he puesto el ejemplo de Juan Ramón, un autor del que el poeta gallego mantuvo diferentes opiniones a medida que se desplazaba el dial de su receptividad creativa. Basta contrastar la diferencia de trato que le otorga al compararlo con Antonio Machado en Las palabras de la tribu. A Valente, reacio a cualquier signo de una subjetividad excesiva, partidario de un yo disidente de sí mismo, le parece más estimulante la «esencial heterogeneidad del ser», propugnada por el Machado de los apócrifos, que la «esencial homogeneidad del yo", aplicada no sin sorna a Juan Ramón, en quien reconoce la espléndida manifestación de una "sentimentalidad clausurada» (II: 105 y 108).Aquí sí cabe recurrir a los versos antes citados: «Esta es la hora, este es el tiempo / — hijo soy de esta historia—", aunque sea en descargo del propio Valente. Tal vez lo temprano de su texto crítico, aparecido en primera instancia en Índice de Artes y Letras en 1957, no le procuró la suficiente perspectiva (o le procuró la perspectiva que marcaba justo el reloj de su tiempo) para valorar en su exacta magnitud las aportaciones del último Juan Ramón, ese que nunca daremos por «clausurado». No hace falta decir que el juicio acabó siendo otro, y no me refiero solo a la estima, sino a las posibilidades germinativas que Valente detecta en la escritura juanramoniana. Por eso encuentro tan reveladora esta semblanza que le dedica en 1981, «El yo y la máscara», entre otras cosas porque se asemeja bastante a un autorretrato: 
Lo amábamos, lo amamos. Por la perfección que nunca se perfeccionaba. Porque no amó jamás al prójimo como a sí mismo. Porque abrió cuando quiso ventanas al sarcasmo. Porque nunca ingresó en la Academia. Porque parió más poesía que cuantos, mal o bien, le sucedieron y él había engendrado. Porque hizo la Obra deshaciéndola.Y así la dejó viva. Porque entró en la vejez sin morir.Y porque la palabra no lo abandonó. Ni él a ella (II: 1304).

Aquello que afirmaba T. S. Eliot en «La tradición y el talento individual» acerca de que el contacto y el diálogo decisivo con los grandes poetas del pasado se produce, no en la etapa impresionable y juvenil de las influencias, sino en el momento en que el gran poeta del presente se enfrenta a su propia obra de madurez (2004: 219), cobra especial sentido en este caso particular. Espacio abrirá significativamente las páginas de Las ínsulas extrañas, del mismo modo que lo hace el verso primero de Animal de fondo con Fragmentos de un libro futuro (2000). Es en este ciclo último, sobre todo, donde la presencia de Juan Ramón se refleja, de manera intermitente, para transparentarse, diluirse, borrarse, junto con el resto de episodios vitales o literarios (ya indistinguibles) que cruzan por estas páginas. Pondré un ejemplo, «Otoño, 1994»: el escenario no es otro que el fantasma del simbolismo; un escenario de-construido, como la figura de Juan Ramón o la del propio autor, animales de fondo ambos, ante los espejos de un diario suspenso en el melancólico borde de los días:

En la ventana

las gotas de lluvia fingen llanto

del prematuro rostro frío de este otoño.

Hay días

en la estación que baja

con las nieblas primeras

hacia la fronda aún verde

del jardín tan íntimo,

velados días como tenues telas,

días tejidos en el hueco oscuro,

suspendidos del borde

de los días iguales,

como ayer, como siempre (I: 554-555). 
Quizás ante un Valente omnímodo y omnívoro convenga hablar menos de influencias que de afinidades electivas.Y entre estas hallaremos, desde luego, a Cernuda: el poeta español que más podía seducirlo en un primer momento por diversas cuestiones. La primera puede resultar paradójica, y es el gusto compartido por aspectos de una lírica ajena como la inglesa, en concreto la amplia línea de tradición meditativa que va de John Donne a T. S. Eliot (Jiménez Heffernan, 2004: 183-192). Lo que encuentra en Cernuda son los tonos y las inflexiones de esa meditación dentro del cauce del propio idioma. Pero hay algo que me parece todavía más decisivo para el joven que escribe Poemas a Lázaro y La memoria y los signos (1966). Cernuda le proporcionó el escenario para integrar forma, idea y subjetividad dentro de la misma secuencia de abstracción poética; esa contradicción que el arte debe resolver en armonía, de igual manera que no es posible distinguir el alma en el cuerpo del poema. Al acercarse al magisterio de Cernuda, Valente, el poeta de la impersonalidad eliotiana y de la anonimia de un diario, empatiza con la voz que habla en La realidad y el deseo y que sabe moldear una distancia con el hombre que relata su experiencia en Historial de un libro. No le interesa el sujeto confesional o biográfico, pero comprende que es el subsuelo ético de dicho sujeto el mecanismo interno que pone en pie aquella estructura meditativa que tanto le importa.

Y entonces entra en juego el mito Luis Cernuda: el más aislado y retraído en su exilio, alérgico al mundo literario, el desolado en su quimera, el que fuera piedra de escándalo contra su propia y famosísima generación. Se mire como se mire, se trata de una postura que en pocos podría tener mejor acogimiento que en Valente. Convencido de que la creación artística solo es realizable desde la óptica de un sujeto sensible, como parte de una comunidad compuesta de seres singulares, creencia casi siempre plasmada en sus primeros libros, Valente acabó por entender la idiosincrasia de la escritura en su última etapa como un hecho acaecido dentro del apartamiento más agudo. En sus Notas de un simulador (1997), apuntaba al respecto: «Es cosa para andar en lo oculto, para echar púas de erizo y quedarse en un agujero sin que nadie nos vea» (II: 460). A Cernuda le dedicó dos ensayos en Las palabras de la tribu, en cierta manera dos retratos morales de la insobornable condición del poeta moderno, de su inevitable soledad; el segundo de ellos, «Luis Cernuda en su mito» (II: 229-231), fue concebido como homenaje 
a raíz de su muerte. Si Cernuda soñó con un poeta futuro, en el cual su pasión se ordenara con nueva medida,Valente no dudaría en arrogarse dicho linaje cuando muchos años después depositara un ramo de siemprevivas sobre la lápida del poeta en el Panteón Jardín de Ciudad de México:

Señor de la distancia y lo imposible.

Luis Cernuda, poeta, reza

la piedra, y los lugares y las fechas

que acotaron tu paso entre los vivos.

Entre ellos soñaste un poeta futuro

$y$ al final lo engendraste

y hoy puede así el futuro hablar contigo (I: 549).

La historia, que va dejando tantos hilos sueltos, logra a veces cerrar un círculo, y en su fin halla su principio. Valente había viajado a México para participar en un congreso y presentar un texto titulado «Poesía y exilio» (II: 678-690); después escribió un poema, «A Cernuda, con unas siemprevivas» (I: 548-549), para incluirlo en un libro último, que tuvo acabamiento solo con la muerte.

Del mismo modo que Valente encarnó acaso el poeta que Cernuda le reclamaba al abismo del tiempo venidero, Paul Celan fue el autor contemporáneo con el que pudo sentirse Valente más identificado dentro de su espacio literario. Sobre todo el espacio de singular apuesta estética que ocuparía a partir de Treinta y siete fragmentos.Valente leyó y tradujo a Celan igual que si se situara frente a un espejo. Así que lo certero sería decir que, más que de una revelación, se trató de una reafirmación, un reconocimiento antes que un conocimiento. Ambos mantuvieron un permanente estado de alerta ante el lenguaje, siempre envuelto en la espesura de una comunicabilidad superficial y desgastada, amenazado por la espesa tiniebla de los discursos vacíos, y, en el caso de Celan, homicidas. De ahí esa tensión interior, que insinúa la vulnerabilidad de una palabra expuesta, y por ello el requisito de blindarla (lo que algunos etiquetaron de hermetismo) para su salvaguarda.

Yo diría que eso es lo que encontramos en un libro que puede considerarse de transición como El inocente (1970), donde se expresa la tenacidad de crear un poema que sea «un objeto metálico / de dura luz, / de púas aceradas, / de crueles aristas»; «un objeto duro, 
/ resistente a la vista, odioso al tacto» (I: 304). Parece un artefacto pensado para mantener a distancia cualquier obediencia gregaria, cualquier consentimiento social, incluyendo, y cito con la provocadora ironía de Giorgio Manganelli, a quienes se sitúan ante el aparato literario y «raspan su epidermis de metáforas hasta que queda expuesto el Espíritu de su Tiempo, ese líquido pútrido y blancuzco: la Weltanschauung» (2014: 273). Dicho poema lo tituló Valente «El poema», lo que supone toda una declaración de intenciones, de la que se desprende además una pregunta: si no logramos erigir un conjunto de signos de semejante complexión, «cuándo podremos poseer la tierra» (I: 304). Poseer la tierra no implica en este caso una Weltanschauung, ni la premisa de un arte comprometido; manifiesta con mayor exactitud un anhelo de lo real absoluto, que diría Novalis. Significa apropiarse del mundo a través de la palabra y la visión poéticas.

No sabemos con certeza cuándo comenzó el «diálogo» entre Valente y Celan. Lo nombra por vez primera en su Diario anónimo en diciembre de 1972, dos años después del fallecimiento de este, por lo que no es ocioso sugerir que tal diálogo discurre por la senda de aquella famosa premisa de Heidegger: «somos una conversación». Valente comenta un verso de Celan, "Palabra, linde de lo oscuro», y se interroga sobre el vocablo que él traduce por «linde»: «Lisene: ¿Linde? ¿Refuerzo? Es una palabra que se usa en arquitectura» (2011:154). Como no podía ser menos, la solidez constructiva de lo poético en relación con la fragilidad de la palabra ocupa el tema de la reflexión.

Sin embargo, le asalta a uno la duda de si Valente, como otros grandes escritores modernos, no sintió la necesidad de desdoblarse (¿yo es otro, otros?) o crearse un heterónimo a través de Celan, figura de condición errante que expresa una traumática escisión: la de quien sobrevive contra la palabra y por medio de la palabra. Sus traducciones del poeta rumano, que escogió el alemán como lengua literaria, son sin duda las que prefiero de entre otras versiones, pero también es cierto que, siendo fieles hasta donde la fidelidad alcanza ("Poetry is what gets lost in translation", sentenció Robert Frost), suenan demasiado valentianas.Y a lo mejor se trata de eso. Por lo que cerraré otro círculo, acudiendo de nuevo a Juan Ramón Jiménez. Este anotó en uno de los numerosos papeles sueltos, comentarios y aforismos que gravitan como materia en torno a su Obra siempre haciéndose: «Únicamente debe traducirse cuando lo que uno lee de otro le sea tan íntimo, tan propio a uno, que sintamos a un tiempo que es de 
uno y no lo es [...], que lamentemos que no sea aquello expresión nuestra. Entonces le damos - debemos darle- forma propia en nuestra lengua, para que sea aquello un poco de uno» (Jiménez, en González Ródenas, 2006: 440). En términos de Juan Ramón, Valente se "apropió» de aquellas parcelas expresivas de Celan que reforzaron su personal desarrollo lírico, apreciando sobre todo lo que llamó la «desfrecuentación de lenguajes gastados» (I: 644). En cuanto a las comparaciones, me parece oportuno recordar lo apuntado por un buen conocedor de ambos poetas, Gómez Toré, quien aclara que Celan «se muestra más audaz en la quiebra del idioma», con un «ritmo cada vez más entrecortado, cada vez más propenso a romper los nexos lógicos y sintácticos» (2017:236).Valente, poseedor de una sensualidad verbal y una apetencia melódica que rara vez se pondera, o se pondera menos en contraste con la gravedad de sus silencios, que parecen preferir sus más devotos exégetas, no sigue del todo a Celan en ciertos tramos que extreman la ruptura; cuando este, digamos, se hace más circense, cuando su ironía es una carcajada terrible, una especie de exclamación paradójica. A eso se referíaVincenzo Vitiello en Los tiempos de la poesía, aludiendo a las complejidades de la lectura de Celan, a lo especial que resulta en aquellas situaciones donde «su phoné está más cerca del ruido que del sonido» (2009: 159).Valente tradujo "Tubinga, enero», el poema en que Celan nos muestra a un Hölderlin que ha convertido su phoné en balbuceo, única posibilidad para el canto del presente y el porvenir:

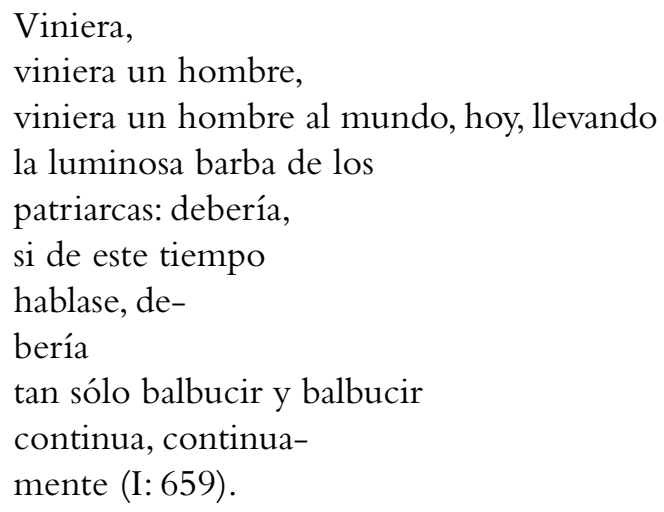

En el original, los dos últimos versos citados dicen: «immer-, immer- / zuzu». Immerzu puede traducirse «continuamente», pero «zuzu» suena parecido a conjuro de brujería, acrobacia lingüística que Valente omite. Por el contrario, la lectura (con evidentes ecos) 
de «Tubinga, otoño tardío, 1991», texto de Fragmentos de un libro futuro, pese a que nos depara también una imagen desmitificadora de la historia, del romanticismo, del espectro de Hölderlin en su torre amarilla o de la sombra que escribe y al escribirse se difumina entre sus propias líneas, no deja de conservar, a su vez, un vestigio de lo sublime; por ejemplo, esos melancólicos restos de palabras flotando sobre el Neckar:

Entre el sauce apenas rozado por las aguas y la torre amarilla, el tiempo mira al tiempo y lo devora. El río lleva lento, hacia lo lejos, imágenes sin nombre, rostros muertos, el ritual aciago del adiós.Y tú, pálida sombra, en la cruel ruina de la memoria encuentras todavía fundamento (I: 544).

Necesidad o requerimiento íntimo.Valente lector y tradu-autor de Celan. Si la tradición palpita en sus «rastros kármicos», la traducción es cambio y movimiento por medio de sus transmigraciones. La literatura rehúsa un domicilio fijo, languidece cuando no encuentra un sitio distinto adonde ir. ¿Por qué no reconocer, entonces, en Celan, prolífico traductor por su parte de Rimbaud, Mandelstam, Pessoa, Emily Dickinson... y cuya propia poesía, según insinuó George Steiner en Después de Babel, viene traducida al alemán, limpia de toda inmundicia histórico-política (2001: 395), ese requerimiento íntimo de ser traducido?

Antes de Celan, antes de la particular Babel de Valente, el autor de $A$ modo de esperanza (1955) había planteado en su debut literario algunos de los motivos que ambos sondearán en su honda concepción de lo poético como un decir que, más allá de la claridad o la tiniebla, está siempre en camino, se dirige hacia algún lugar. Citaré «La rosa necesaria»:

La rosa no, ni la palabra sola.

La rosa que se da de mano en mano, que es necesario dar, la rosa necesaria, la compartida así, la convivida, la que no debe ser 
salvada de la muerte,

la que debe morir

para ser nuestra,

para ser cierta.

Plaza,

estancia, casa

del hombre,

palabra natural,

habitada y usada como el aire del mundo (I: 85).

Celan llamó a uno de sus grandes libros precisamente La rosa de nadie. De él traduce Valente estos versos: «Una nada / fuimos, somos, seremos, / floreciendo: / rosa de / nada, de nadie. / Con / el pistilo almalúcido, / cielo desierto el estambre, / la corola roja / de la palabra purpúrea que cantamos / sobre, oh sobre / la espina» (I: 662). La clara identificación entre rosa y palabra no es lo que me propongo señalar, sino ese punto de partida antimetafisico en dos autores que confieren una dimensión trascendente al suceso lírico. La rosa-palabra no puede, «no debe ser / salvada de la muerte», «debe morir» para resultar por completo humana y cierta. Para Celan, que sabe que la poesía aspira a abrirse paso a través del tiempo, pero no puede hacerlo por encima del tiempo, somos una «nada» que ambiciona florecer mediante esa misma "palabra purpúrea» sobre la espina del mundo: un desafío que no nos librará de la muerte, pero tal vez nos justifica.

Si pretendemos una mejor interpretación de «La rosa necesaria», conviene poner otra vez de relieve que la obra inicial de Valente tampoco pretende pasar por encima de su tiempo, comparte con otros escritores coetáneos la preocupación ante ese «solar» de palabras desmoronadas, que esperan ser alzadas de entre las ruinas. Las expresiones referidas a la rosa "que se da de mano en mano», «la convivida», la "habitada y usada como el aire del mundo» traducen el afán de latido que lo ata a una circunstancia de la que no desea desligarse. Pero, por otro lado, la propia naturaleza de su escritura concentra una meditación sobre la palabra poética que le otorga una amplitud de miras ajena a los intereses literarios de su tiempo: «Plaza, / estancia, casa / del hombre, / palabra natural» (I: 85). Muchos años después, Valente regresará, en Tres lecciones de tinieblas, a esa casa de la palabra; lo hará inserto en una contemplación más radical y ensimismada, atendiendo al espíritu de la letra, pero sobre todo a su materialidad, que es la contenedora del espíritu en sí. 
«Bet», el poema que me dispongo a transcribir, hace referencia a todo ello, pues, además de configurar la letra segunda del alfabeto hebreo, porta el significado de casa. Si el lenguaje es la morada del ser, la poesía lo será del lenguaje:

Casa, lugar, habitación, morada: empieza así la oscura narración de los tiempos: para que algo tenga duración, fulguración, presencia: casa, lugar, habitación, memoria: se hace mano lo cóncavo y centro la extensión: sobre las aguas: ven sobre las aguas: dales nombre: para que lo que no está esté, se fije y sea estar, estancia, cuerpo: el hálito fecunda al humus: se despiertan, como de sí, las formas: yo reconozco a tientas mi morada (I: 397).

Si atendemos a sus Tres lecciones de tinieblas, toda la escritura de Valente se desliza entre la letra «Bet», la casa o morada del lenguaje, y la que apunta a la condición ineludible en él de lo exílico, «Guimel»: «El movimiento: exilio: infinito regreso: vértigo: el solo movimiento es la quietud» (I:397). Entonces ¿hacia dónde se dirige ese decir de lo poético, siempre en camino? Desde luego, la respuesta está lejos de ser precisa, se presenta llena de incertidumbre, pero de una incertidumbre que en el caso de Valente alberga siempre una esperanza. Podría poner algunos ejemplos, pero estoy pensando sobre todo en la manera significativa y memorable con que cierra un libro, asimismo significativo y de cierre de su trayectoria inicial, como La memoria y los signos. Frente a la conciencia de falibilidad de los signos, se deposita en estos la expectativa alentadora que declara el título del poema «No inútilmente»:

No hemos llegado lejos, pues con razón me dices que no son suficientes las palabras para hacernos más libres.

Te respondo

que todavía no sabemos hasta cuándo o hasta dónde puede llegar una palabra, quién la recogerá ni de qué boca con suficiente fe para darle su forma verdadera (I: 219).

ParaValente la poesía consistió en ocupar o invocar un lugar; o lo que es lo mismo, sugerir la posibilidad de la existencia de este. Dónde, cuándo o quién le dará «su forma verdadera» no parecen preguntas 
que aguarden una respuesta inmediata. Escribir literatura no es exactamente un gesto social, y su destinatario es siempre un destinatario provisional o ambiguo; un público, advierte Giorgio Manganelli, de «lectores imprecisos, lectores que aún tienen que nacer, lectores destinados a no nacer nunca, lectores ya nacidos y muertos» (2014:275). De entre todos los lectores posibles, el que menos interesó aValente fue el apresurado, el que busca el refugio del mensaje como simple vehículo de expresión de ideas. Ese reduccionismo lo combatió el poeta en «Comunicación y conocimiento» (II: 39-46), el ensayo de Las palabras de la tribu que conecta de manera más intencionada con los debates literarios de su generación. Pero al margen de la sintonía con otros escritos del mismo cariz protagonizados entonces por Carlos Barral o Jaime Gil de Biedma, me sigue pareciendo Celan el mejor complemento para la lectura de estos versos. En su «Discurso de Bremen» (1958), Celan elaboró una hermosa metáfora para tratar de explicar o imaginar "hasta dónde puede llegar una palabra», "quién la recogerá», cuándo. La comparó a una botella arrojada al mar (y cito de nuevo por la versión de Valente), «abandonada a la esperanza - tantas veces frágil, por supuesto- de que cualquier día, en alguna parte, pueda ser recogida en alguna playa, en la playa del corazón tal vez» (I: 648). Tachados de herméticos ambos poetas en numerosas ocasiones, acaso no represente una geografía insólita para «el lugar del canto» esa playa futura del corazón.

\section{LA PALABRA SUMERGIDA}

En una página de Mandorla sitúa Valente una breve composición que condensa de manera singular sus expectativas de lo poético: «No estamos en la superficie más que para hacer una inspiración profunda que nos permita regresar al fondo. Nostalgia de las branquias» (I: 424).

La poesía y la palabra viven en la exigencia de una inmersión, prolongada y abisal, mientras que la brecha que nos separa de la presencia y el sentido queda expresada en una melancólica aspiración. La poesía es nostalgia de unas branquias.Valente tituló este texto «Il tuffatore», haciendo con ello referencia al célebre fresco de la tumba del nadador en la antigua ciudad griega de Paestum. No hace mucho tuve la ocasión de contemplar con detalle las imágenes del sepulcro en la sala del museo arqueológico que lo alberga. Afuera, 
el cielo del crepúsculo en la Campania se posaba como manso animal sobre los templos. En su interior, desde el otro lado de la mirada, unas pinturas hilaban en delicada trama lo visible con lo invisible.

Entonces uno comprende, hasta donde ello resulta posible, el enigma de esta aquilatada poética en Valente. El salto que el nadador ejecuta desde la losa que sirve de techo al sarcófago parece comunicarlo con un asombroso simposio de dioses o de hombres, cuyo prodigio aguarda representado en las paredes de la cámara. Pero no es la metáfora plástica del tránsito de la vida terrenal a lo eterno, con sus resonancias órficas, lo que centra el interés del autor. Lo hace la misteriosa corriente de aguas ondeantes, rodeada de un fondo blanco, en que se sumerge el tuffatore: un símbolo plausible de aquella otra realidad en que nos sumerge la experiencia estética. Al igual que la urna griega de Keats, otro objeto que encierra el secreto de la verdad y la belleza, he aquí la única forma de metafisica que explorará Valente, una metafisica del arte en la estela de Nietzsche o Heidegger.

Hacia qué dominios inmersiona el nadador, o dirige nuestros sentidos, es algo que nos propone descifrar un poema de Interior con figuras (1976), "Consideración de la mirada»:

\author{
Miraba hacia un lugar que nunca \\ podría estar del lado \\ menos real de la mirada.
}
Miraba desde dentro de la luz de un sueño como el ángel andrógino de la melancolía (I: 340-341).

De nuevo una apelación a ese sedimento de nostalgia, de melancolía; el mismo al que se refiere Roger Bartra en La melancolía moderna, provocada por un mundo escindido e incoherente. La melancolía "que envuelve con su aura negra los fragmentos, los ilumina a todos con una luz saturnina y, con ello, les da una apariencia de unidad» (2019:10). Pero ¿qué unidad?, cabe preguntarse. Nuestra modernidad científica es la primera cultura que ha establecido sobre la separación, la dispersión sucedida tras el estallido primigenio, el relato de su origen. En Valente, poeta de lo fragmentario, la melancolía de una unidad imposible (esa que existe tan solo «dentro de la luz de un sueño») o la nostalgia de las branquias para desenvolverse entre los 
fragmentos que apuntalan un mundo, se convierten en una forma de interrogar al lenguaje:

\author{
Dime \\ con qué rotas imágenes ahora \\ recomponer el día venidero, \\ trazar los signos, \\ tender la red al fondo... (I: 377).
}

Interrogarlo no para hallar respuestas, sino para discernir un ámbito de posibilidades para la escritura, algo que consiste, según nos sugiere, en «tender la red al fondo». Valente se asoma una y otra vez a un mundo y un tiempo de imágenes rotas, con ellas teje la red de signos de una poética que merodea la experiencia de restaurar el sentido, pero que rechaza, por falaces, las realidades compactas. Se trata de aproximaciones, deliberadamente incompletas, a una biografia inmersa en la historia: «Tiempo de guerra» (I: 193-194), "Lugar vacío en la celebración» (I: 282-283); a una identidad que se confunde con la biografía del mundo: según sucede en Material memoria y No amanece el cantor; o bien a citas, traducciones, textos, cartas, versos ajenos de los que se apropia como fragmentos de voces que han perdido su significado originario o que apenas lo recuerdan. En la hendidura de una subjetividad y una realidad fracturadas, en su desarraigo, su ofuscación o extrañeza, Valente tantea un espacio para el canto, ese lugar, ya sabemos, que una vez fue «solar prodigioso de una casa más grande» (I: 150). Enunciado así, «solar» y no "casa", evoca un sitio ruinoso, desértico. Sin embargo, lo erosionado hace aparecer un paisaje, permite concebir una alternativa fructífera. Estoy pensando en el Valente más reconocible, donde el símil de la desposesión mística genera una gramática de depuración verbal; y cómo no aludir también al Valente que redescubre el desierto jabèsiano en el profundo sur (Andújar Almansa, 2011:143-158); o el autor que reúne por vez primera su obra bajo el epígrafe de Punto cero (1972), el punto en el que lo dicho debe recomenzar a decirse, pero no como quien deja atrás un "prodigioso» monumento de palabras, sino rescatando de entre las ruinas aquellos materiales que aún sirvan de combustión al lenguaje.

Una forma de leer aValente es desde las contradicciones que irradia un centro perseguido por él de exhaustiva coherencia. Rehusó tanto los esquemas del realismo como las categorizaciones poéticas de la realidad. Si atribuyó a la poesía la capacidad de ver junto lo 
disgregado, no fue a través de una mirada esencialista, sino mediante la búsqueda de lo intersticial, una fórmula de simbolismo asimétrico que fue moldeando a su medida. Así, al preguntarse por el «tiempo de miseria» que impone la historia al poeta, el Dichter in dürftiger Zeit del Hölderlin de "Pan y vino", en que brilla con luz propia la analogía de la "frágil vasija» para contener lo numinoso, Valente, situado también él ante un escenario de ruinas, contesta con la rotundidad de «El cántaro» (I: 134), composición que anticipa su idea de la palabra-materia, desplazando la metáfora de Hölderlin hacia una imagen objetual del poema: "El cántaro y el canto», que solo "existe conteniendo", que logra la «suprema / realidad de la forma» (I: 134) cuando hospeda la plenitud. Contra todo pronóstico se alza y tiene esperanza lo poético. Se alza porque conserva siempre algo que decir, o hace aparecer un espacio para que pueda ser dicho en algún otro tiempo. Por eso seguimos oyendo a Hölderlin, pese a que lo acompañara la percepción de que dictaba sus elegías a un círculo de estatuas del pasado. Por eso no hemos terminado aún de oír a Valente.

Una prueba de que todavía continúa su decir, y nosotros debemos permanecer a la escucha, la tenemos en que plantea cuestiones que no han llegado a ser entendidas del todo por sus detractores, ni tampoco por aquellos que se han erigido en su guardia pretoriana póstuma. La profunda relación intelectual que Valente mantuvo con la mística de todas las religiones, y su búsqueda de la raíz de una expresión originaria, la expresión de un descenso a la noche oscura del lenguaje, ha propiciado que términos que conllevan de por sí un alto riesgo literario como el silencio o lo inefable se hayan convertido, al ser objeto de una menguada exégesis, en auténticas cargas de profundidad y en dudosos tópicos sobre su obra y su magisterio. Pienso que medir la verdadera importancia de Valente tal vez requiera una aproximación que consiste en un doble movimiento: primero, el de desplazarse entre las continuas y sustanciosas correspondencias que conectan el fruto de su palabra-creativa con el dilatado horizonte desplegado por su palabra-pensamiento. En segundo término, discernir hasta qué punto esta última enriquece el análisis y comprensión artística de la primera, o termina, por el contrario, mediatizándola. Incluso ambas cosas.

La excepcional síntesis lograda entre reflexión y creación le ha permitido a Valente situarse desde una posición de fuerza crítica; indicar una pauta acerca de cómo deseaba ser leído. No se trata de 
un reproche. Así lo hizo también Juan Ramón Jiménez, marcando sus tiempos o etapas con aquel memorable striptease poético de "Vino primero pura», o mediante el tránsito de sus sucesivos mares como estaciones líricas de llegada.Y fue el caso parecido de Juan de la Cruz, a quien Valente reivindicó ante una crítica que había optado por excluir, como quien se quita un problema de encima, los comentarios místicos del carmelita, reduciendo al puro asombro literario el contrapeso de fuerzas lingüísticas y espirituales que levantan el complejo edificio del Cántico o de Llama de amor viva. Desde luego, tenía razón Valente al incidir en ese equilibrio constructivo hecho de dualidades, puesto que él mismo edificó, a su vez, un espacio de confluencias para su obra. No podemos culparlo de que pretendiese evitar que el sentido de su palabra se convirtiera en flecha sin blanco. Aunque tampoco conviene poner en duda el poder de la intuición en los grandes poetas; esa intuición que resulta una imaginación doble, y que en alguien como Valente impide que las meditaciones teóricas o la intencionalidad artística se transformen en doctrina a la hora de adentrarse en el misterio del proceso creativo, propio o ajeno.

Ensanchar su escritura en ambas direcciones supuso también para Valente un esfuerzo por recomponer la palabra despedazada de nuestra modernidad. Es cierto que en su búsqueda de una convergencia entre poesía y pensamiento encontró fértiles modelos en autores que habilitaron una expresión híbrida para emitir indicios no revelados por el discurso filosófico. No obstante, lo que resulta una empresa monumental en Heidegger o María Zambrano admite en cierto modo el reconocimiento de un fracaso, si pensamos en las observaciones hechas por Giorgio Agamben en su libro Estancias:

La poesía posee su objeto sin conocerlo y la filosofia lo conoce sin poseerlo. La palabra occidental está dividida así entre una palabra inconsciente y como caída del cielo, que goza del objeto del conocimiento representándolo en la forma bella, y una palabra que tiene para sí toda la seriedad y la conciencia, pero que no goza de su objeto porque no sabe representarlo (1995: 12).

Como poeta,Valente gozó sin duda de su objeto y lo representó «en la forma bella»; no lo hizo de una manera irreflexiva, según demuestra el énfasis de su obra ensayística, pero supo establecer un fluido de pensamiento que suspende cuando es preciso la racionalidad, 
que deja su espacio a la "palabra inconsciente y como caída del cielo». Esto significa que Valente no vaciló en los límites. Por eso se identificó con el lema de Novalis: «Tanto más poético, tanto más verdadero».

Frecuentar a Valente es acostumbrarse a deambular por un extraño dominio hecho de diáfanas iluminaciones y experiencias sumergidas. Nos concedió episodios líricos deslumbrantes y pobló de pistas una prosa de pensamiento artístico al alcance de muy pocos entre sus contemporáneos. Valente es el maestro de los límites. Así lo asegura la cita de Arnaut Daniel que eligió para Fragmentos de un libro futuro: «Yo soy Arnaut que amontona el viento / y caza la liebre con el buey / y nada contra corriente» (I: 541).Yo soy Arnaut o yo soy Valente. En "La memoria y el fuego», texto aparecido en Variaciones sobre el pájaro y la red (1991), niega para volver a afirmar, rechaza para atraer un nuevo sentido: «Empieza la palabra poética en el punto o límite extremo en que se hace imposible el decir. Empieza en lo imposible» (II: 430); y añade unas líneas después: «¿No sería lo imposible la metáfora de un posible que infinitamente nos rebasa?» (II: 431). La experiencia de modular verbalmente lo inefable, o la de preguntarse cómo hablar de lo que no se puede decir, está lejos de conducir al enmudecimiento en los autores que de verdad importan, dígase Valente, dígase Kafka, dígase Rilke en las Elegias de Duino, cuyo Ángel preserva intemporal algo que nos ha sido arrebatado u ocultado. Valente interpretó el silencio poético de muy diversas maneras, metáfora rebosante de alternativas que se complementan. Lo entendió como forma de vaciar la palabra de sus diversos estratos culturales, sociológicos, retóricos: estratos superpuestos como adiposidades informativas o estilísticas. Al hacer esto libera al lenguaje y le confiere una disponibilidad ilimitada, lo carga de porvenir. Ese porvenir hace que todos los libros deValente sean en realidad fragmentos de libros futuros. Lejos de impulsar una negatividad extrema, su voz nunca se extingue, cumpliendo así la promesa establecida desde unos versos de Material memoria:

Mientras pueda decir no moriré.

Mientras empañe el hálito las palabras escritas en la noche no moriré (I: 386). 
Valente descubrió en el silencio que no hace enmudecer un valioso aliado compositivo. Interesado en la obra de Schönberg y Webern, vinculó la estética de la concisión musical con la de una poética (imagen o palabra) que se retrae y nos retrae frente a la inflación de mensajes y el basurero virtual de nuestra época. Componer el silencio, eso que Anton Webern logró (y cito piezas predilectas del poeta) en Trío de cuerda o Concierto para nueve instrumentos, equivale en términos valentianos a aquellas otras formulaciones que dio a su palabra sumergida: "cortedad del decir», «retracción», «voz no identificable»; sinónimos, siempre me lo ha parecido, de un pudor de espíritu.En "Cuatro referentes para una estética contemporánea» (1996), ensayo crucial para comprender las afluencias que desembocan en la luminosa constelación de su obra última, una constelación en rotación perpetua, el poeta cita a Pierre Boulez explicando el arte de Webern: «Todo su esfuerzo consiste en aislar el sonido, en tratarlo por sí mismo. Y lo consigue sea rodeándolo de silencio o utilizando grandes intervalos. El silencio invade a veces toda una página de orquesta, con la sola excepción de algunos fragmentos diseminados» (II: 554).Valente, quien confiesa que la escritura musical de Webern «tal vez haya marcado mi propia poesía más que ninguna otra escritura contemporánea» (II: 554), opera con un método análogo. Primero, porque no resulta descabellado establecer paralelismos entre la atonalidad y la estética del fragmento, tan cara a su estilo. Pero, sobre todo, por la forma en que Valente integra el silencio en el territorio del signo poético: esa zona de amplitud más decisiva que la sola palabra, pues incluye el cuerpo de la palabra y la sombra proyectada por esta, el ritmo de su circulación sanguínea junto al intervalo de los latidos. Sombra que cobija los significados menos visibles y por ello más magmáticos, intervalos que participan con sus pulsaciones de la sintaxis poética.

Una muestra del interés que despierta en Valente la música de Webern la tenemos en un texto de Mandorla: "Versión de Trakl-Webern» (I: 435). El autor no se limita, como en otras ocasiones, a hacer una traducción del poema «Die Sonne» de Greorg Trakl; nos indica que el estímulo para traducirlo arranca de su musicalización en forma de lied para cuatro instrumentos por parte de Webern, que lo incluye en su Opus 14.

En «Cerámica con figuras sobre fondo blanco» (I: 341), primera muestra metapoética de esa estética del silencio, Valente sugiere resaltar la figura del signo, esto es, la fulguración poética, no los 
significados, aislándola en el metafórico fondo blanco de un jarrón chino. Pero si tuviera que discernir un libro en que con mayor necesidad de la forma se plasma ese arte de composición a través del silencio, sería No amanece el cantor. En la parte primera, de título homónimo, tenemos veintidós suites secretamente conectadas mediante los espacios en blanco que se distribuyen alrededor; no separando, ni sirviendo de transición, sino envolviendo. Tales espacios funcionan como una sístole y diástole de la propia escritura: ... oír, en silencio, el silencio repleto de sentidos del mundo... trazar los signos... regresar a la escucha en que se sumerge (no amanece) el cantor.

Lo que nos aguarda en la sección segunda, «Paisaje con pájaros amarillos», es quizá la mejor elegía de la lírica española del siglo xx con la salvedad de Llanto por Ignacio Sánchez Mejías de Lorca. Desde su comienzo se anuncia un imposible diálogo, que sin embargo va a acaecer: no solo entre la vida y la muerte, o entre lo que nosotros podamos decir ante el silencio de la muerte, sino también por cómo nos habla la muerte tan callando: «De tu anegado corazón me llega, como antes tu voz, el vaho oscuro de la muerte. Habítame con ella. Ni siquiera la muerte pueda de mí jamás arrebatarte» (I: 497).

«Corazón», «voz»: latido.Y el «vaho oscuro», el vaho que se posa sobre la página igual que si empañara la superficie de un espejo: no nos refleja, pero permite escribir o hacer incisiones sobre él: «Paisaje sumergido [...] Entré con pie descalzo y no te hallé.Tú, sin embargo, estabas. No me viste. No teníamos ya señal con que decirnos nuestra mutua presencia. Cruzarse así, solos, sin verse. Pájaros amarillos. Transparencia absoluta de la proximidad» (I: 498). A lo largo de «Paisaje con pájaros amarillos», compuesto tras la muerte de su hijo Antonio, los espacios entre secuencia y secuencia semejan puentes tendidos sobre un abismo. Puentes que (in)comunican la palabra con la no-palabra "del otro lado», aquella que ha sido igualmente pronunciada. Pero conforman también la necesidad de una pausa, un modo de tomar aliento dentro del canto, preparándonos para oír lo que viene de la sombra:

TARDE final. Declina pálida la luz. Yo fluyo desde la herida abierta en mi costado hacia el endurecido río de tus venas.

Convergencia. La hoja cae sobre la hoja, la lluvia en la extensión total del llanto. 
Un hombre lleva las cenizas de un muerto en su pequeño atadijo bajo el brazo. Llueve. No hay nadie. Anda como si pudiera llevar su paquete a algún destino. Se ve andar. Se ve en una paramera sin fin. Al término, el ingreso devorador lo aguarda del ciego laberinto.

¿Qué son esas nubes, dime, que el viento arrastra como cabelleras al término encendido de la tarde? ¿Hiciste tú ese camino? ¿Sin mí lo hiciste? ¿Cuándo? (I: 498-499).

Pese a su estremecedora elegía,Valente no apeló al silencio poético para apostar por el rostro del vacío, ni aparcó su voz ante el umbral de lo infranqueable. Prefirió a Webern antes que la teatralidad de las partituras en blanco de John Cage en 4'33'. Su propuesta de lo conciso se traduce en una apertura máxima al sentido. La afirmación de Agamben: «El lenguaje custodia lo indecible, diciéndolo» (2008: 31) me parece el punto de partida mejor para entender esa inefabilidad, custodiada con un halo de fuego por la poesía. Lo inefable reposa en los depósitos latentes del lenguaje; lo que duerme bajo la superficie de este se manifiesta en el mundo visible del significante. Valente coincide con Agamben, precediéndolo, en Las palabras de la tribu, donde comenta: «lo indecible busca el decir» (II: 87). Lo hace en un texto titulado precisamente «La hermenéutica o la cortedad del decir», publicado por vez primera en 1969, un ensayo premonitorio en muchos aspectos, pues contiene en germen alValente en que más quiso reconocerse Valente. Así, cuando declara que toda operación poética converge a «lo umbilical», o que deviene «en un esfuerzo por perforar el túnel infinito de las rememoraciones para arrastrarlas desde o hacia el origen» (II: 82), parece estar conduciéndonos, tunelando capas de experiencia individual y colectiva, hacia el descenso al limo originario, a la materia, a la memoria umbilical del mundo, a otra de las acepciones de su palabra sumergida.

Pero me interesa ahora lo que quiso indicarnos con «cortedad del decir», eso que él sabe que consiste en una paradoja; el arco de expresión tensado al máximo entre la aparente insuficiencia de la palabra y la sobreabundancia de contenido que esta acoge.Y aunque Valente lo asegure, ¿de veras es siempre así? ¿En Siete representaciones (1967) o Palais de Justice (2014) no resultan admirables por sí solas las formas que puede desplegar la sobreabundancia del significante, esa energía verbal asentada en el poder gravitatorio de las imágenes o en su arsenal metafórico? En cualquiera de los casos, el arco tensado 
arroja su saeta: «En el punto de máxima tensión, con el lenguaje en vecindad del estallido, se produce la gran poesía, donde lo indecible como tal queda infinitamente dicho» (II: 87).

Reflejo de esas tensiones que disparan a la infinitud son los espléndidos duelos que atraviesan Material memoria, uno de sus libros más intensos y originales, más lleno de descubrimientos. Duelos simbólicos entre luz y oscuridad, entre lo visible y lo no visible, entre voz y aliento, entre cuerpo y lindes, entre forma y las formas sin forma del fondo. Pero asimismo entre la escritura deValente y la pintura de Tàpies, con esos «Cinco fragmentos para Antoni Tàpies»: un texto-llave que cierra el poemario para abrirlo de nuevo pleno de resonancias. Se trata de contraposiciones en las que ninguno de los elementos en juego logra imponerse a su opuesto, ya que eso supondría una dualidad o una ruptura que se descarta. Poeta de la inmanencia, poeta de la materia, no concibió esta sin la pulsión de hacerla trascender, de interiorizarla. Pero ¿cómo? En uno de los aforismos de Notas de un simulador señala: «El espíritu es la metáfora de la infinitud de la materia» (II: 460), y en un comentario de La experiencia abisal (2004) aclara sus relaciones con lo inefable: «La noción de inefabilidad se basa, precisamente, en la idea de que hay un mundo de realidad que el lenguaje no puede expresar. Pero esa realidad está sumergida en el lenguaje mismo, constituye su urgrund, su fondo soterrado, al que nos remite incesantemente la palabra poética» (II: 712). Si la expresión mística pugna por dar corporalidad al ectoplasma de una experiencia, la poesía supone la tentativa de hacer emerger el cuerpo de lo real sumergido.

En la mística de Valente siempre hay un cuerpo del amor o del delito.Aunque sea el cuerpo despedazado de Teresa de Ávila, del que nos habla en "Escatología y gloria de la carne» (II: 414-422), uno de esos ensayos que te hacen pensar en Bataille como discípulo aventajado de Valente. «Solo se llega a ser escritor cuando se empieza a tener una relación carnal con las palabras» (II: 459), escribe en Notas de un simulador. Esa simbiosis entre cuerpo y palabra, con sus inmersiones, sus descensos, sus estallidos de la materia, sus fulgores, incluso su fantasmagoría y su ruina, componen, si adoptamos la expresión de Roland Barthes, los «fragmentos de un discurso amoroso»: algo así como otro anhelo de unidad escindida, y por ello de iluminación melancólica. «Pliegue de la materia / en donde reposaba / incandescente el solo / residuo vivo del amor» (I: 384). La experiencia erótica, la mística más fiable y afirmadora del poeta, admite los intervalos de 
silencio que rodean a la carne: el tiempo, la identidad desfigurada, el borde de los cuerpos: «Nada quedaba de la música / que no fuera tu cuerpo en el reposo / que ha seguido al amor» (I: 385); también los forcejeos entre las palabras que escriben el cuerpo del amor y el cuerpo destinado a orquestar otra escritura:

Luego del despertar
y mientras aún estabas
en las lindes del día
yo escribía palabras
sobre todo tu cuerpo.

Luego vino la noche y las borró.

Tú me reconociste sin embargo.

\author{
Entonces dije \\ con el aliento sólo de mi voz \\ idénticas palabras \\ sobre tu mismo cuerpo \\ y nunca nadie pudo más tocarlas \\ sin quemarse en el halo de fuego (I: 385 ).
}

Valente, que había ensayado en Mandorla la disolución de la identidad en una poética del eros (verbo y vulva) — «Cuando al amanecer en tu deriva encuentro / fragmentos de mí mismo naufragados / y a tientas vuelvo a entrar en tus entrañas» (I: 416)—, empleará el sortilegio de su maestría lírica para convertir el lecho del amor que escandaliza las salas en que transcurre el litigio de Palais de Justice en arrasado solar, zona cero, sitio del que emerge el desafio de un canto al margen de la moral burguesa y los contratos sociales:

¿Estábamos aquí en el umbral antiguo de los dioses? El sol caía vertical e impío sobre el más puro vértice de ti. Tu cintura tenía la vibración secreta de la sierpe en el lecho revuelto. Los derrocados dioses, la erosión interminable de los capiteles, la súbita inmersión de una estatua en el mar. ¿Por dónde? ¿Adónde? Nacía de las sábanas pegadas a tu cuerpo una tenue palpitación. ¿Adónde ir más allá de este sueño? ¿Para qué, sobre la lenta putrefacción del día en las afueras de todo lo que no es este lugar, hacer otro dosel? La mierda arruina reptante los restos de la Acrópolis. En el naufragio, este hundimiento aquí, en tu lecho, por debajo del nivel de la muerte, burlándola, nos hace respirar. Habría que descender 
aún, bajar aún más adonde no llegasen nunca los excavadores, adonde no se oyera nunca ni el rumor de un paso que pudiese alterar la perfección del despertar. Lentas empiezan las caricias mientras Tebas, la bien fundada, se derrumba hasta las raíces de sí. Los dioses de la adivinación escuchan en suspenso el dorado rumor con que la orina baja desde tus piernas, corre por mi sexo, deja en mi boca su sabor agraz (2014: 63-64).

En Palais de Justice, extenso poema en prosa de fondo autobiográfico (signifique esto último lo que signifique), Valente vincula el fracaso del contrato social a las limitaciones del pacto verbal: de ahí que extreme los elementos experimentales de un texto que linda con lo surreal y lo onírico. Quizá por eso su alusión a «los excavadores» - futuros arqueólogos de una pasión amorosa destinada a sepultar toda una acrópolis junto con sus leyes y sus dioses - sugiere, entre otros motivos, un rechazo a las exhumaciones practicadas por el adocenamiento de cierta crítica literaria, presente y futura. No obstante, su poética, al igual que la del «Punto cero» de Lautréamont y Rimbaud (I: 315) o la de Mallarmé, consistió en un denuedo continuo de excavar en los abismos del verso. En una nota de su Diario anónimo fechada en 1984, el mismo año en que hace por vez primera referencia a la redacción de Palais de Justice, expone este argumento: «Las palabras crean espacios agujereados, cráteres, vacíos. Eso es el poema» (2011:229).

La elocuencia de los poetas se desliza por los extremos de la profecía o la conjetura.Valente prefirió la conjetura. La que nos propone acerca de los «espacios agujereados» del poema parece una buena muestra. El lenguaje indaga en el lugar desahuciado de lo que no existe, pero esa poética del hueco o el vacío no (des)compone una estética nihilista. Es algo en lo que quiero insistir acudiendo de nuevo a las reflexiones de su Diario anónimo: «Dondequiera que llegues verás que algo ha sido derribado, algo que yerra sin reposo en el exilio invisible. Es el dios de la diferencia, el dios del lugar» (2011:241). A nadie escapa que estas palabras, anotadas en 1986, preludian el título de su libro Al dios del lugar (1989), un libro que, distanciándose de las sacralizaciones y los nihilismos estériles, expresa esa nostálgica aspiración que antes atribuí al poeta: la de una ausencia que, de manera indefinida, invita a la presencia: «Sólo en la ausencia de todo signo / se posa el dios» (I: 464). 
Segunda conjetura. El lenguaje se ausenta de aquello que existe pero no resulta visible, pues lo suplanta la herramienta de un habla oxidada. Así, en la secuencia XXXIV "(Un testigo)», de Treinta $y$ siete fragmentos, Valente relaciona esa falta de sustancia significativa o simbólica con una suerte de estatismo vital. Las dificultades que afrontaba el «lado / menos real de la mirada» en Interior con figuras se equiparan en el fragmento a la simplificación degradadora de la realidad como consecuencia de un déficit semántico, lo que refleja con inequívoco rechazo la expresión «rumiando fatigados la saliva» (I: 334). Aunque todavía me parece más decisivo el modo en que plantea la posibilidad, siempre conflictiva, de acercarse al acontecimiento o la revelación, así como el hecho de que nosotros la dejemos pasar de largo. El testimonio de otra realidad «distinta o más secreta» (I: 334), la resurrección de Lázaro en estos versos, se convierte en un episodio del que los presentes, «los vecinos apelotonados cerca del tapial» (I: 334), no alcanzarán «más que la sola forma natural del suceso» (I: 335 ). Sin duda, la poesía y el arte ofertan la posibilidad de dicha realidad "distinta» de una manera privilegiada, aunque igualmente problemática, y «la sola forma natural del suceso» equivale en su caso a la trivialidad denotativa. Frente al óxido de los mensajes, Valente reivindicó en otro de sus Treinta y siete fragmentos la «luminosa opacidad de los signos» (I: 335), una paradoja sobre la que sí logra posarse el sentido.

Valente, que en «Un testigo», al igual que en tantos poemas de su primera etapa, entre ellos el excepcional «La llamada» (I: 116-117), se mete en el traje de un Lázaro laico, alguien apremiado a un particular estado de conciencia (Andújar Almansa, 2011:125-132), comprendió pronto que la labor del poeta exigía rescatar a la palabra de la tumba de los lugares comunes. Eso incluyó los clichés literarios de su tiempo, de cada uno de sus tiempos, circulantes como moneda que solo adquiere baratijas, «compraventa de ruidos usados» (I:314). Al final, su idea de la poesía acabó transmitiendo la sensación de algo que está siempre a punto de decirse, suspendido en el trampolín del lenguaje como la imagen del tuffatore. Pero de un lenguaje situado en los precipicios del lenguaje.

«El ángel andrógino de la melancolía», que es el ángel de la palabra, una palabra que regresa cuando su sentido ya no se reconoce, y en cuyo olvido habita la memoria, otorga la certidumbre que lo impulsa desde $A$ modo de esperanza hasta su creación última, la más quebrantada y melancólica, Fragmentos de un libro futuro. Allí es 
posible intuir ya el límite de la apuesta: «El día en que este juego sin fin con las palabras se termine habremos muerto» (I: 544). Valente dio por acabado el juego tras un conjunto final de poemas que se advierte más consciente que nunca del auténtico proceso íntimo de su escritura; esa respiración sumergida, con inevitables incursiones a la ondeante superficie en blanco de la página. 


\section{BIBLIOGRAFÍA}

AA.VV. (2002). Las ínsulas extrañas. Antología de poesía en lengua española (19502000), eds. Eduardo Milán, Andrés Sánchez Robayna, José Ángel Valente y Blanca Varela, Barcelona, Galaxia Gutenberg / Círculo de Lectores.

Agamben, Giorgio (1995). Estancias. La palabra y el fantasma en la cultura occidental, Valencia, Pre-Textos.

— (2008). El lenguaje y la muerte. Un seminario sobre la negatividad,Valencia, Pre-Textos. Ajmátova, Anna y Marina Tsvetáieva (2005). El canto y la ceniza. Antología poética, eds. Monika Zgustova y Olvido García Valdés, Barcelona, Galaxia Gutenberg / Círculo de Lectores.

Andújar Almansa, José (2011). «El limo y la ciudad celeste», en El guardián del fin de los desiertos. Perspectivas sobre Valente, eds. José Andújar Almansa y Antonio Lafarque, Valencia, Pre-Textos, pp. 117-158.

Bartra, Roger (2019). La melancolía moderna, Valencia, Pre-Textos.

Eцiot, T. S. (2004). «La tradición y el talento individual», en El bosque sagrado, ed. José Luis Palomares, San Lorenzo de El Escorial, Cuadernos de Langre, pp. 217-239.

Gómez Toré, José Luis (2017). «Después de Auschwitz, después de Hiroshima: Celan leído porValente», en Lecturas de Paul Celan, eds. Mario Martín Gijón y Rosa Benéitez Andrés, Madrid, Abada, pp. 229-247.

González Ródenas, Soledad (2006). «La biblioteca de Juan Ramón Jiménez: donosos y grandes escrutinios», en Juan Ramón Jiménez, Premio Nobel 1956, eds. Javier Blasco y Antonio Piedra, Madrid, Sociedad Estatal de Conmemoraciones Culturales / Residencia de Estudiantes, pp. 427-443.

Jiménez HefFernan, Julián (2004). Los papeles rotos. Ensayos sobre poesía española contemporánea, Madrid, Abada.

Manganelli, Giorgio (2014). La literatura como mentira, Barcelona, Dioptrías. Paz, Octavio (1999). La casa de la presencia. Poesía e historia. Obras completas I, Barcelona, Galaxia Gutenberg / Círculo de Lectores.

Speranza, Graciela (2017). Cronografías. Arte y ficciones de un tiempo sin tiempo, Barcelona, Anagrama.

Steiner, George (2001). Después de Babel. Aspectos del lenguaje y la traducción, México, Fondo de Cultura Económica.

VALEnte, José Ángel (1963). Sobre el lugar del canto (1953-1963), Barcelona, Colliure. 
- (2002). Cuaderno de versiones, ed. Claudio Rodríguez Fer, Barcelona, Galaxia Gutenberg / Círculo de Lectores.

- (2006). Obras completas I. Poesía y prosa, ed. Andrés Sánchez Robayna, Barcelona, Galaxia Gutenberg / Círculo de Lectores.

— (2008). Obras completas II. Ensayos, ed. Andrés Sánchez

Robayna, recopilación e introducción Claudio Rodríguez Fer, Barcelona, Galaxia Gutenberg / Círculo de Lectores.

— (2011). Diario anónimo (1959-2000), ed. Andrés Sánchez Robayna, Barcelona, Galaxia Gutenberg / Círculo de Lectores.

- (2014). Palais de Justice, ed. Andrés Sánchez Robayna, Barcelona, Galaxia Gutenberg / Círculo de Lectores.

- (2018). El ángel de la creación. Diálogos y entrevistas, ed. Andrés Sánchez Robayna, Barcelona, Galaxia Gutenberg.

Tabarovsky, Damián (2018). Fantasma de la vanguardia, Madrid, Mardulce.

Vitiello,Vincenzo (2009). Los tiempos de la poesía, Madrid, Abada.

Weinberger, Eliot (2012). Las cataratas, ed. Aurelio Major, Barcelona, Duomo. 